\title{
Effects of zinc and molybdenum on European Bluestar (Amsonia orientalis): An in vitro study
}

\author{
Arda Acemi ${ }^{1 \star}$, Yonca Avcı Duman², Yonca Yüzügüllü Karakuş ${ }^{1}$ and Fazıl Özen ${ }^{1}$
}

\begin{abstract}
This study aimed to investigate the effects of possible zinc ( $\mathrm{Zn}$ ) and molybdenum (Mo) contaminations on the critically endangered European Bluestar (Amsonia orientalis). The effects of $\mathrm{Zn}$ and Mo were tested in a dose-dependent manner on in vitro cultures. $\mathrm{Zn}$ at $0.1 \mathrm{mM}$ in the medium inhibited root development whereas Mo showed the same effect only at $\geq 2.5 \mathrm{mM}$ concentration. Gradual inhibition of shoot development was observed after treatment with both metals. Protein contents were also negatively affected by increasing metal concentrations, while proline levels increased gradually. Successive increases in metal concentrations resulted in higher hydrogen peroxide $\left(\mathrm{H}_{2} \mathrm{O}_{2}\right)$ and malondialdehyde (MDA) concentrations. The activity of the antioxidant enzymes, peroxidase (POD) and catalase (CAT), were found to be enhanced in response to increasing metal concentrations. Superoxide dismutase (SOD) activity decreased after Zn treatment but increased after Mo treatment. A marked increase in POD and CAT in response to metal stress suggests that these enzymes might have a significant cooperative role in regulating $\mathrm{H}_{2} \mathrm{O}_{2}$ production, although CAT, in response to drought and salt stress, has been reported to only play a supplementary role in A. orientalis. These results indicated that A. orientalis is susceptible to long-term $\mathrm{Zn}$ stress but can tolerate up to 2.5 $\mathrm{mM}$ Mo in the long-term. Deficiency of Mo is more common than high toxic concentrations in the environment. Therefore $\mathrm{Zn}$ contamination should be considered as one of the major threats for A. orientalis in its native habitat.
\end{abstract}

Keywords: Molybdenum, oxidative stress, Rhazya, tissue culture, zinc

${ }^{1}$ Department of Biology, Faculty of Arts and Sciences, Kocaeli University, 41380 İzmit, Kocaeli, Turkey

${ }^{2}$ Department of Chemistry, Faculty of Arts and Sciences, Kocaeli University, 41380 İzmit, Kocaeli, Turkey

*Corresponding author: A. Acemi E-mail: arda.acemi@kocaeli.edu.tr

DOI: 10.2478/ebtj-2020-0005

\section{Introduction}

Amsonia orientalis Decne. (syn. Rhazya orientalis (Decne.) A. DC.) which is also known as "BlueStar", "European BlueStar" or "Eastern Rhazya" is a herbaceous perennial plant with star-shaped, pale blue-colored flowers from the Apocynaceae (Dogbane) family (1). Amsonia species are mainly cultivated as garden plants in Europe and the USA for their ornamental merit. The species prefers moist and loamy soils, usually close to streams. The chemical properties of the soil where A. orientalis is native were evaluated, and the zinc $(\mathrm{Zn})$ content was found between 1.06 and $1.50 \mathrm{ppm}$. However, there is no data about the molybdenum (Mo) content of the soil (2). The natural populations of the species have a range limited to parts of Turkey and Greece and are considered to be very rare. The species has been under conservation for almost 40 years after it was listed among the plant species to be conserved at the European scale by The Bern Convention of the European Council (3). It is also considered as one of the critically endangered (CR) species in The Red List by The International Union for Conservation of Nature (IUCN). At present, the range of wild A. orientalis is known to be restricted to Northwest Turkey and Northeastern Greece. The decrease in its habitat may be related to anthropogenic and/or environmental abiotic factors. To investigate the effects of salt and drought stress on the growth and physiology of A. orientalis, several studies have been conducted (4,5). However, the effects of heavy metal contamination, which is a major global environmental problem, on A. orientalis have not yet been assessed. 
Heavy metals can be found in the environment since they are naturally occurring elements of the Earth's crust. However, motor vehicle emissions, landfilling, industrial waste disposal, mining activities, extensive use of agricultural chemicals, and domestic effluents contribute to heavy metal input to the environment (6). Heavy metals can accumulate in organisms through the food chain. Although ionic forms of some heavy metals are essential trace elements necessary for normal biological function in both plants and animals, in higher concentrations, they can exert toxic effects (7). Two of these beneficial metals, $\mathrm{Zn}$ and Mo, are available for plants as ionic zinc $\left(\mathrm{Zn}^{2+}\right)$ and molybdenum oxide $\left(\mathrm{MoO}_{4}^{2-}\right)$ forms, respectively. $\mathrm{Zn}$ is critical in the structure of copper-zinc superoxide dismutase (Cu-Zn-SOD), and it plays a role in phytohormone production, cytochrome, chlorophyll, and nucleotide biosynthesis. Molybdenum plays a role in the active centers of all molybdenum enzymes, except bacterial nitrogenase, after it is complexed by a ubiquitous pterin-based molybdenum cofactor (Moco) (8). Mo also takes part in nitrogen fixation, sulfate assimilation, purine degradation, nitrate reduction and abscisic acid (ABA) biosynthesis $(7,9)$. The combustion of fossil fuels, wastewaters from industrial processes, the transportation of ores, and distribution of sewage are the main reasons for Mo release to the environment while most $\mathrm{Zn}$ is released to the environment during industrial activities, such as mining, coal and waste combustion and steel processing. In the environment, increased soil pH triggers Mo uptake in plants, which may lead to excess accumulation-related Mo toxicity (10). In contrast, higher soil $\mathrm{pH}$ generally decreases $\mathrm{Zn}$ absorption. Thus lower soil $\mathrm{pH}$ is generally associated with the increased $\mathrm{Zn}$ uptake, and under these conditions, $\mathrm{Zn}$ may build up to toxic concentrations in plants (11). Heavy metal stress, like other abiotic stresses, may trigger the production of hydrogen peroxide $\left(\mathrm{H}_{2} \mathrm{O}_{2}\right)$, superoxide $\left(\mathrm{O}_{2}^{-}\right)$, singlet oxygen $\left({ }^{1} \mathrm{O}_{2}\right)$ and hydroxyl radicals $(\cdot \mathrm{OH})$, all of which are reactive oxygen species (ROS). ROS can lead to cellular damage by oxidizing cellular components, inhibiting several enzymes, damaging RNA and DNA synthesis and integrity, and peroxidizing membrane lipids (12).

Plants can neutralize the adverse effects of stress factors through both enzymatic and non-enzymatic defense systems. Enzymatic defenses include catalase (CAT), peroxidases (guaiacol and ascorbate peroxidase: POD), and superoxide dismutase (SOD) as antioxidants, while carotenoids, glycine betaine and proline, some phenolic compounds, polyamines, and sugar alcohols compose the most important non-enzymatic defense mechanisms. The extent of cellular membrane damage due to ROS-dependent lipid peroxidation can be estimated by evaluating malondialdehyde (MDA) content (13). Plants can tolerate the deleterious effects of stress factors until their defensive systems become overwhelmed. The concentrations of stressors, such as heavy metals, which will exceed the protective function of the defensive systems varies from stressor to stressor. However, long-term and/or severe stresses may cause growth reduction, which could eventually result in plant loss. Analysis of plant development and physiological changes due to alterations in protein and proline contents, ROS production, MDA accumulation, and antioxidant enzyme activities can elucidate the defensive ability of $A$. orientalis against stressors, which in this study were $\mathrm{Zn}$ and Mo.

\section{Material and Methods}

\section{Plant material preparation and in vitro stress treatment}

Amsonia orientalis is distributed in four different localities, Gaziosmanpaşa, Paşa Alanı, Adnan Menderes and Ömerli districts, in the Balikesir province of Turkey. As part of a previous conservation study, A. orientalis specimens from all localities were sampled, and a voucher specimen was deposited in the herbarium of Uludağ University (BULU, specimen no: 18138). The specimens were then transported and planted into the garden at the Umuttepe Campus of Kocaeli University. The number of these individuals was increased through an in vitro propagation study (1). To determine the genetic consistency among these populations in Balıkesir province, Gürkanl et al. (14) conducted a detailed genetic study, and genetic variation was found between the four different populations. Therefore, only individuals from the Gaziosmanpaşa population were propagated and employed in this study to ensure genetic stability and homogeneity among plantlets. The shoots were sampled from propagated mature individuals, and nodal explants, having at least one node, were employed in in vitro primary cultures. The nodal explants were prepared and surface sterilized as described previously by Acemi et al. (15). The explants were then propagated in $\mathrm{Mu}$ rashige and Skoog (MS) medium (16) with $1 \mathrm{mg} \mathrm{l}^{-1}$ 6-benzylaminopurine. The medium was supplemented with $30 \mathrm{~g} \mathrm{l}^{-1}$ sucrose and $7 \mathrm{~g} \mathrm{l}^{-1}$ of plant agar, and the $\mathrm{pH}$ was adjusted to 5.7 before autoclaving. The 1-month-old nodal explants from in vitro shoots were inoculated into MS medium without any treatment (control) and with increasing concentrations of additional $\mathrm{Zn}$ or Mo at 0.1, 0.5, 1.0, 2.5, 5.0 and $10.0 \mathrm{mM}$, prepared with zinc sulfate $\left(\mathrm{ZnSO}_{4} \cdot 7 \mathrm{H}_{2} \mathrm{O}\right)$ or sodium molybdate $\left(\mathrm{Na}_{2} \mathrm{MoO}_{4}\right)$. The cultures were incubated under predefined conditions as previously described (1) for 30 days. The upper cut-off for $\mathrm{Zn}$ and Mo concentrations were determined according to the morphological results of a preliminary study conducted previously. This preliminary study showed that, at concentrations above $10.0 \mathrm{mM}$ for both metals, plant material production was dramatically restricted. Thus the upper limit of the metal concentrations was set at $10 \mathrm{mM}$.

\section{Culture conditions and root and shoot growth assessment}

Five nodal explants were inoculated per culture vessel together with $40 \mathrm{ml}$ of MS medium. Thirty explants were tested in each treatment. Morphological data were collected after 30 days of incubation. Biochemical experiments were performed at the end of the incubation period, after collection of plant materials. Shoots and roots were sampled together to be used in the biochemical assays, unless otherwise indicated. All experiments were performed in triplicate. 


\section{Preparation of crude extract from plant samples}

The plant samples were homogenized in an extraction buffer which consisted of $50 \mathrm{mM}$ sodium phosphate ( $\mathrm{pH}$ 7.0) buffer with $0.1 \mathrm{mM}$ ethylenediaminetetraacetic acid (EDTA). The homogenates were filtered and then centrifuged at 14,000 $\mathrm{g}$ for $15 \mathrm{~min}$ at $4{ }^{\circ} \mathrm{C}$. The process continued by collection of supernatants, which were then used as a crude extract for the assays. To minimize a possible activity loss risk, extract preparation and enzyme activity assays were performed on the same day. Spectrophotometrical assays were done using Smartspect 3000 spectrophotometer (Bio-Rad, CA, USA).

\section{Determination of total soluble protein content}

The method of Bradford (17) was followed to estimate total soluble protein content. Bovine serum albumin was used as the standard. Tissue samples $(250 \mathrm{mg}$ ) were ground in a sterile mortar containing cold Tris- $\mathrm{HCl}$ buffer (10 mM, pH 6.8). The final mixture in the mortar was centrifuged at 15,000 $\mathrm{g}$ for 20 min, and the resulting supernatant was used for the assay.

\section{Determination of free proline content}

Free proline content was estimated following the method of Bates et al. (18). The leaves $(0.5 \mathrm{~g})$ were homogenized in a cooled sterile mortar containing $10 \mathrm{ml}$ of $3 \%$ sulfosalicylic acid, and the homogenate was filtered through Whatman No. 2 filter paper. The filtrate was mixed with acid ninhydrin and glacial acetic acid (1:1:1 v/v), and the mixture was incubated at 100 ${ }^{\circ} \mathrm{C}$ for one hour. The reaction was terminated on ice, and the final mixture was extracted using toluene. The absorbance of the extract was read at $530 \mathrm{~nm}$.

\section{Determination of malondialdehyde content}

The MDA content was estimated using thiobarbituric acid (TBA) reaction, according to the method of Neto et al. (19) after some modifications. Equal volumes $(0.4 \mathrm{ml})$ of TBA reagent and the crude extract were mixed and the obtained mixture incubated at $95{ }^{\circ} \mathrm{C}$ for $15 \mathrm{~min}$. At the end of the incubation period, the reaction was terminated immediately in an ice bath, and then the mixture was centrifuged at $1,500 \mathrm{~g}$ for $15 \mathrm{~min}$. The absorbance of the supernatant was read at 532 and $600 \mathrm{~nm}$. The amount of MDA was calculated from the extinction coefficient of $155 \mathrm{mM}^{-1} \cdot \mathrm{cm}^{-1}$.

\section{Determination of $\mathrm{H}_{2} \mathrm{O}_{2}$ content}

The $\mathrm{H}_{2} \mathrm{O}_{2}$ contents were estimated according to the method of Doupis et al. (20) with some modifications. The reaction mixture containing $0.1 \%(\mathrm{w} / \mathrm{v})$ trichloroacetic acid (TCA), $1 \mathrm{M}$ potassium iodide, $0.5 \mathrm{ml}$ of crude extract, and $50 \mathrm{mM}$ sodium phosphate buffer ( $\mathrm{pH} 7.0$ ) in the final volume of $2.5 \mathrm{ml}$ was kept in the dark for $60 \mathrm{~min}$. Then the absorbance was measured at $390 \mathrm{~nm}$ using a $0.1 \%(\mathrm{w} / \mathrm{v})$ TCA solution and pure catalase reagent as a blank to ensure zero interference. The calculation of $\mathrm{H}_{2} \mathrm{O}_{2}$ contents was done using a standard curve prepared with known $\mathrm{H}_{2} \mathrm{O}_{2}$ concentrations.

\section{Determination of antioxidant enzyme activities}

The method of Dhindsa et al. (21), based on the inhibition of photochemical reduction of nitroblue tetrazolium (NBT) at $560 \mathrm{~nm}$, was used to estimate SOD activity. One unit of SOD activity was defined as the amount of enzyme required for $50 \%$ inhibition.

The pyrogallol oxidation method of Kar and Mishra was used to estimate POD activities (22). Enzyme activity was calculated using the extinction coefficient $2640 \mathrm{M}^{-1} \cdot \mathrm{cm}^{-1}$ at 425 $\mathrm{nm}$ for pyrogallol. One unit of POD activity was defined as the formation of $1 \mathrm{mg}$ of purpurogallin per $5 \mathrm{~min}$.

The method of Aebi (23) based on the calculation of the absorbance of the $\mathrm{H}_{2} \mathrm{O}_{2}$ disappearance rate at $240 \mathrm{~nm}(\varepsilon=0.039$ $\mathrm{cm}^{2} \cdot \mu \mathrm{mol}^{-1}$ ) was used to estimate CAT activity. One unit of CAT activity was defined as the amount of enzyme which catalyzed the decomposition of $1 \mu_{\mathrm{mol}} \mathrm{H}_{2} \mathrm{O}_{2}$ per minute.

\section{Statistical analysis}

Mean values were compared using Duncan's multiple range test at $p<0.05$ significance level. Data were given as mean \pm standard deviation (SD). IBM SPSS Statistics 19 software was used for statistical analysis.

\section{Results}

\section{Morphometric analysis of plant development}

The $\mathrm{Zn}$ treatments above $1.0 \mathrm{mM}$ concentration reduced the mean shoot number and length. The highest shoot number was found from the medium with 0.1 and $1.0 \mathrm{Zn}$, while these treatments gave statistically the same results (Fig. 1a). The mean shoot number then decreased below the control group. The lowest level of $\mathrm{Zn}$ did not significantly affect root induction, but $0.5 \mathrm{mM} \mathrm{Zn}$ treatment caused a dramatically reduced result (Fig. 1a). Mean root length also decreased with increasing $\mathrm{Zn}$ concentrations with root development being completely inhibited above the $0.5 \mathrm{mM}$ concentration (Fig. 1c). However, mean shoot length increased at 0.5 and $1.0 \mathrm{mM} \mathrm{Zn}$ concentrations but gradually reduced with higher concentrations of $\mathrm{Zn}$ (Fig. 1c).

Mo concentrations above $1.0 \mathrm{mM}$ concentrations started to show adverse effects on the shoots of $A$. orientalis. However, the mean shoot number significantly increased in the presence of Mo at 0.1-5.0 mM in the medium. The highest mean shoot number was observed from the medium with $0.1 \mathrm{mM}$ Mo. Starting from the $0.5 \mathrm{mM}$ concentration, the mean shoot number gradually decreased and was similar to that observed in the control group in the presence of $10.0 \mathrm{mM} \mathrm{Mo} \mathrm{(Fig.} \mathrm{1b).}$ Mean shoot length was found to be statistically the same as the control group when exposed to Mo between 0.1-1.0 mM concentration. Dramatic decreases were observed above $1.0 \mathrm{mM}$ concentration (Fig. 1d). The mean root number also reduced gradually with increasing Mo concentrations, and root production was inhibited in the presence of 5.0 and $10.0 \mathrm{mM}$ Mo in the medium (Fig. 1b). Mean root length was also negatively affected by elevated Mo concentrations, gradually decreasing with increasing concentrations of Mo below $5.0 \mathrm{mM}$ (Fig. 1d). 

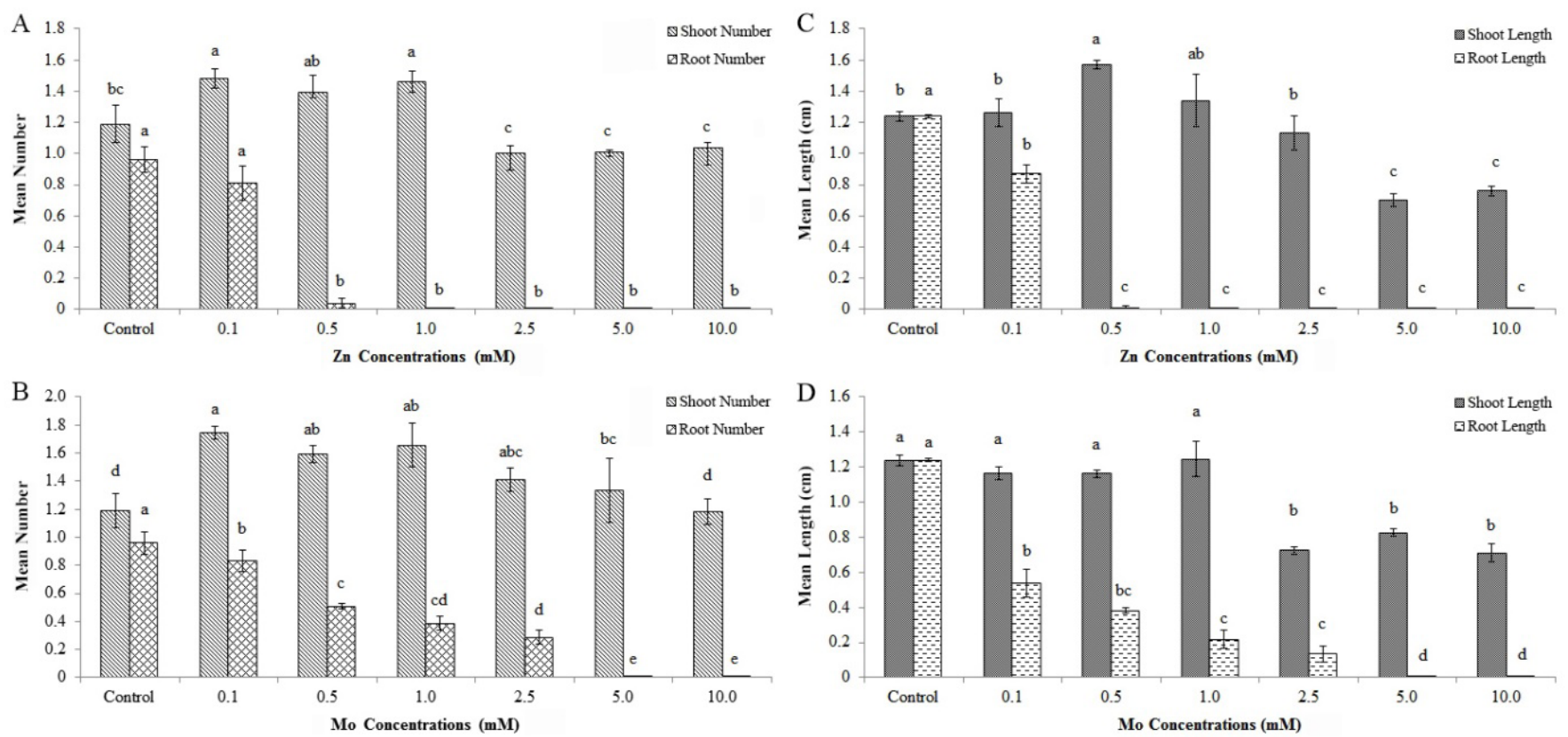

Figure 1. Effects of in vitro $\mathrm{Zn}$ and Mo exposure on shoot and root numbers, and lengths of Amsonia orientalis. Mean shoot and root numbers after Zn exposure (a); Mean shoot and root numbers after Mo exposure (b); Mean shoot and root lengths after $\mathrm{Zn}$ exposure (c); Mean shoot and root lengths after Mo exposure (d). Values are represented as means \pm SD; different letters denote significant differences at $p<0.05$.
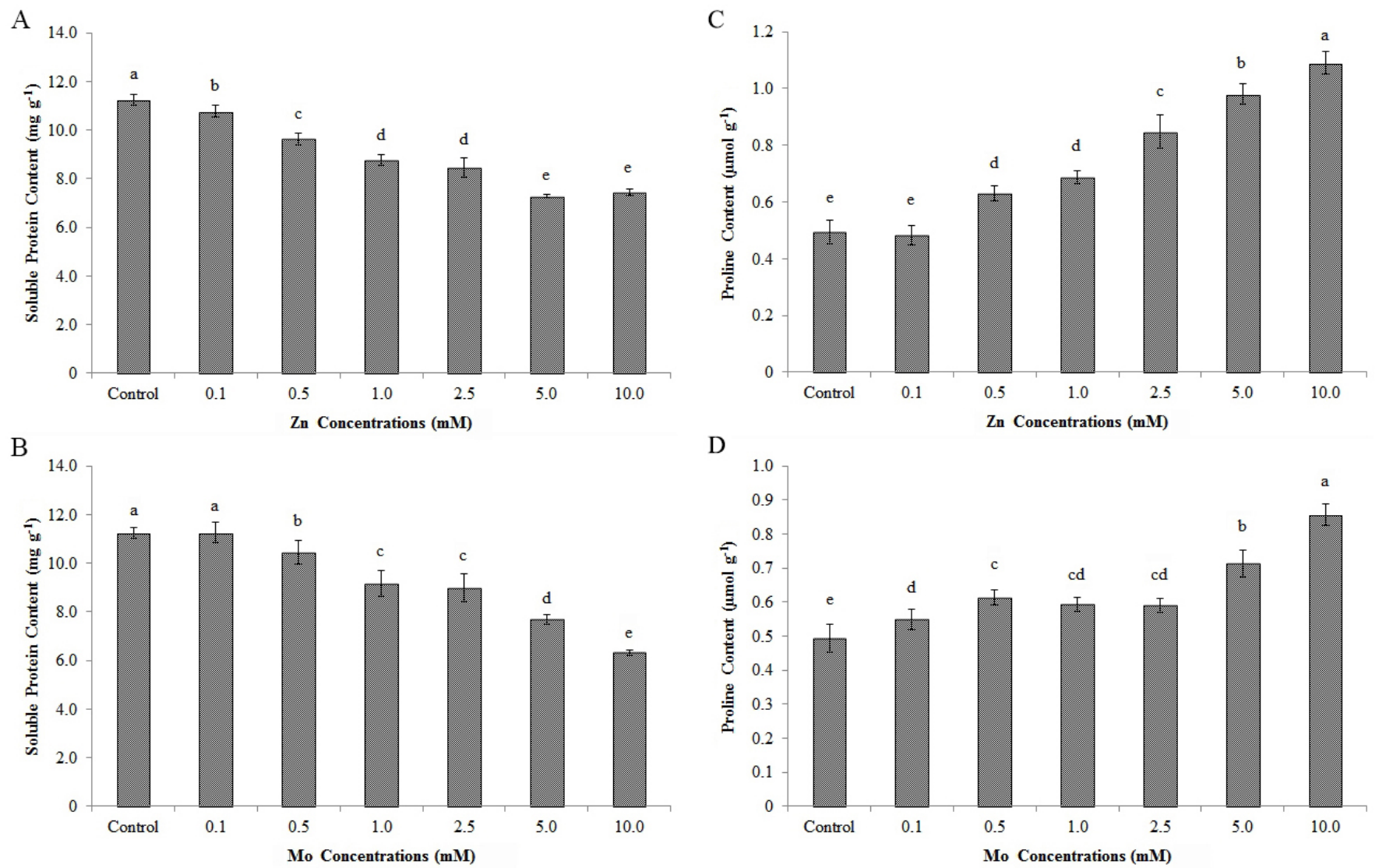

Figure 2. Changes in the soluble protein and prolin contents of Amsonia orientalis as a result of in vitro treatment with $\mathrm{Zn}$ and Mo. Soluble protein content after Zn exposure (a); Soluble protein content after Mo exposure (b); Proline content after Zn exposure (c); Proline content after Mo exposure (d). Values are represented as means \pm SD; different letters denote significant differences at $p<0.05$. 

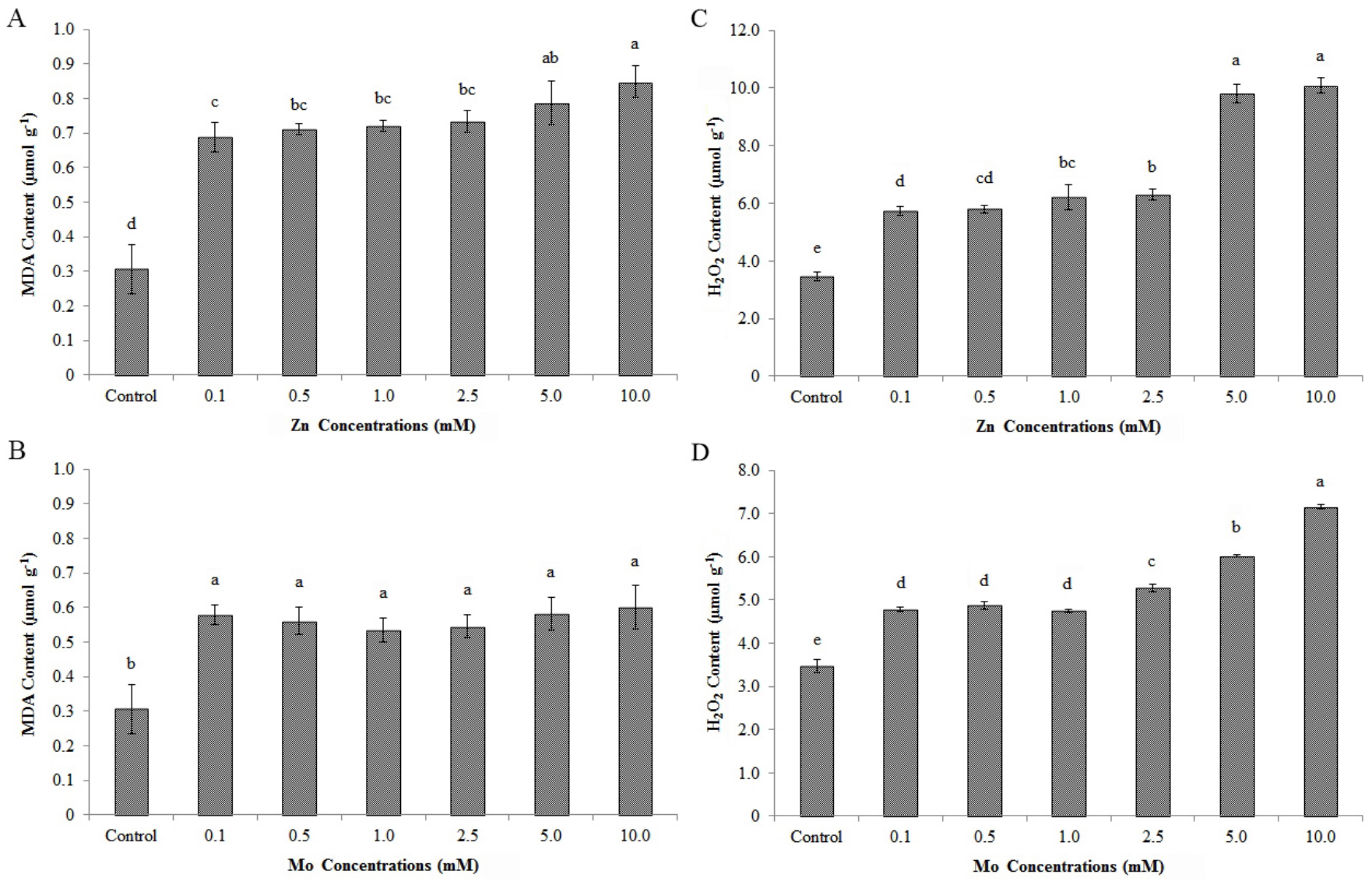

Figure 3. Changes in malondialdehyde (MDA) and hydrogen peroxide $\left(\mathrm{H}_{2} \mathrm{O}_{2}\right)$ contents in Amsonia orientalis as a result of in vitro treatment with $\mathrm{Zn}$ and Mo. MDA content after $\mathrm{Zn}$ exposure (a); MDA content after Mo exposure (b); $\mathrm{H}_{2} \mathrm{O}_{2}$ content after $\mathrm{Zn}$ exposure (c); $\mathrm{H}_{2} \mathrm{O}_{2}$ content after Mo exposure (d). Values are represented as means $\pm \mathrm{SD}$; different letters denote significant differences at $\mathrm{p}<0.05$.

\section{Total soluble protein, and free proline content}

The changes in soluble protein contents due to $\mathrm{Zn}$ and Mo exposure are shown in Fig. $2 \mathrm{a}$ and $2 \mathrm{~b}$, respectively. The control group had the highest protein contents, while increased metal concentrations negatively influenced this parameter. The lowest level of Mo did not significantly affect the protein content, compared to the control group. In all metal treatments, both 1.0 and $2.5 \mathrm{mM}$ concentrations gave the statistically same results.

The changes in proline contents of $A$. orientalis after $\mathrm{Zn}$ and Mo treatments are shown in Fig. 2c and 2d, respectively. Exposure to $\mathrm{Zn}$ induced more proline accumulation than did Mo exposure. The highest proline concentration was found in plants grown in the medium with concentrations of $10.0 \mathrm{mM}$ of either metal while the control group had the lowest concentration of proline per unit weight of fresh plant material. Mo exposure induced a statistically significant increase in proline content even at $0.1 \mathrm{mM}$ concentration. However, proline content at Mo concentrations between 0.5 and $2.5 \mathrm{mM}$ was statistically similar.

\section{Lipid peroxidation-dependent MDA production, and $\mathrm{H}_{2} \mathrm{O}_{2}$} content

The changes in MDA contents of $A$. orientalis due to $\mathrm{Zn}$ and Mo treatments are shown in Fig. $3 a$ and $3 b$, respectively. The highest MDA accumulation was found in the plants treated with $10.0 \mathrm{mM} \mathrm{Zn.} \mathrm{MDA} \mathrm{levels} \mathrm{showed} \mathrm{an} \mathrm{upward} \mathrm{trend} \mathrm{with}$ increasing concentrations of both metals, compared to the control group. However, all Mo concentrations gave statistically the same results, while MDA contents increased as Zn concentrations increased. Nevertheless, the accumulation levels caused by 0.5 and $2.5 \mathrm{mM} \mathrm{Zn}$ concentrations were not statistically different. Additionally, MDA production was more pronounced in the presence of additional $\mathrm{Zn}$ in the medium.

The changes in $\mathrm{H}_{2} \mathrm{O}_{2}$ contents of $A$. orientalis after $\mathrm{Zn}$ and Mo exposure are shown in Fig. 3c and 3d, respectively. All treatments significantly increased $\mathrm{H}_{2} \mathrm{O}_{2}$ accumulation in a dose-dependent way. However, statistically non-significant results were observed in the plants treated with 0.1-1.0 mM Mo. $\mathrm{Zn}$ treatments gave closer results when applied at moderate concentrations (0.1-2.5 mM). Both metals induced the highest $\mathrm{H}_{2} \mathrm{O}_{2}$ accumulations after they were applied at $10 \mathrm{mM}$ concentration. Also, $5.0 \mathrm{mM} \mathrm{Zn}$ induced statistically similar $\mathrm{H}_{2} \mathrm{O}_{2}$ accumulation to $10 \mathrm{mM}$. In general, $\mathrm{Zn}$ exposure triggered stronger $\mathrm{H}_{2} \mathrm{O}_{2}$ production than that seen with Mo exposure.

\section{Effects of metal stress on antioxidant enzyme activities}

The metal stress-dependent alterations on SOD enzyme activities of $A$. orientalis are summarized in Fig. $4 a$ and $4 b$ for $\mathrm{Zn}$ and Mo, respectively. All experimental Mo concentrations 

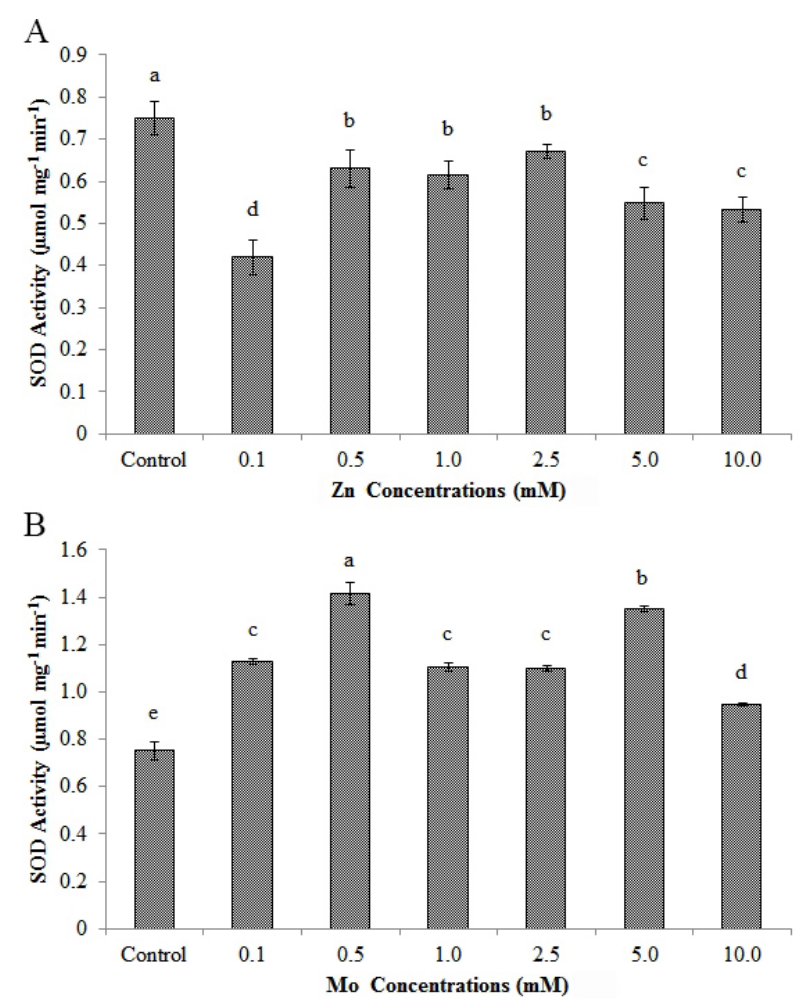

Figure 4. Changes in superoxide dismutase (SOD) activity in Amsonia orientalis as a result of in vitro treatment with $\mathrm{Zn}$ and Mo. SOD activity after Zn exposure (a); SOD activity after Mo exposure (b). Values are represented as means \pm SD; different letters denote significant differences at $p<0.05$.
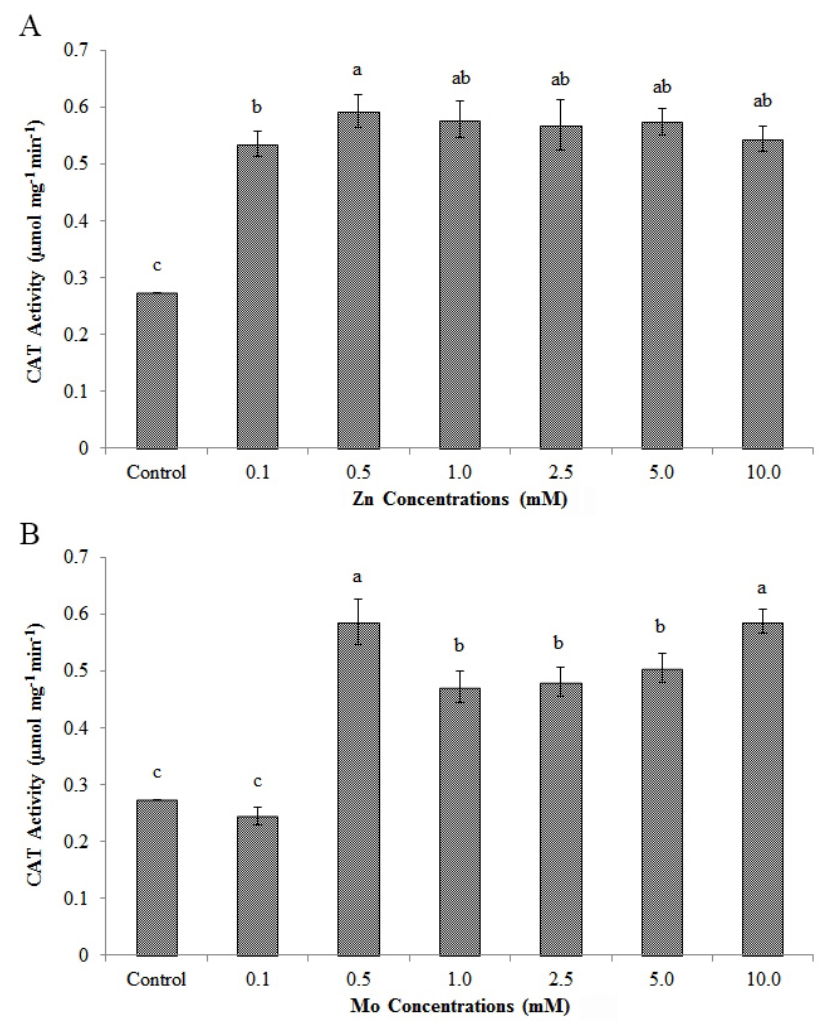

Figure 6. Changes in catalase (CAT) activity in Amsonia orientalis as a result of in vitro treatment with $\mathrm{Zn}$ and Mo. CAT activity after Zn exposure (a); CAT activity after Mo exposure (b). Values are represented as means \pm SD; different letters denote significant differences at $\mathrm{p}<0.05$.
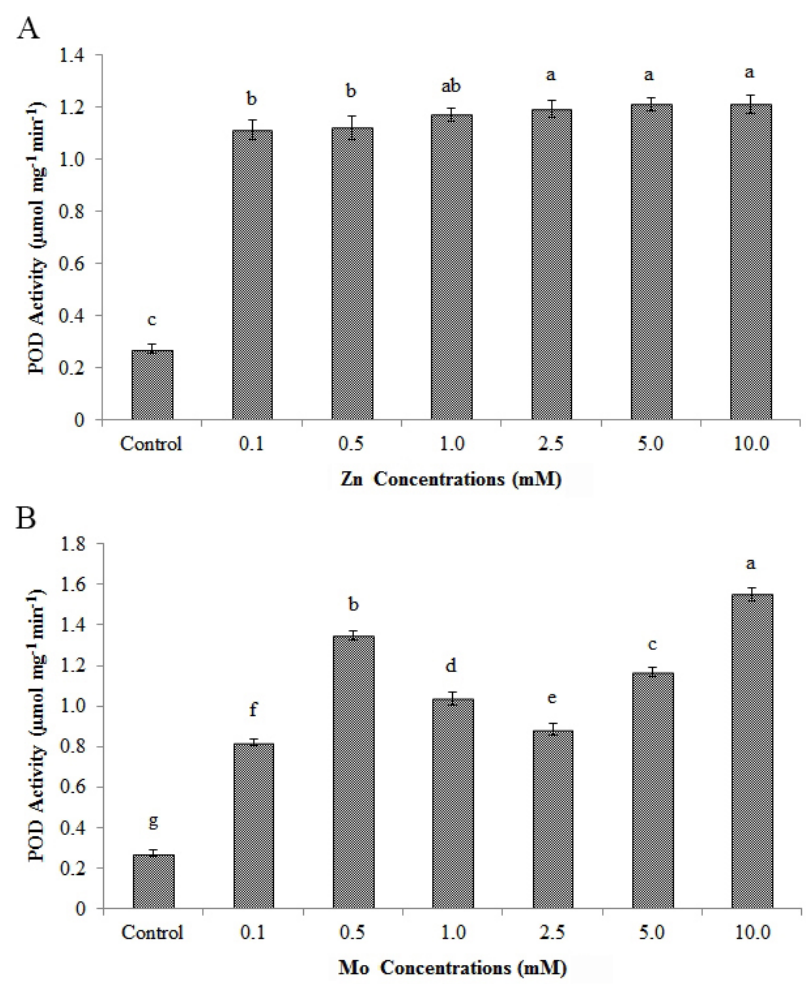

Figure 5. Changes in peroxidase (POD) activity in Amsonia orientalis as a result of in vitro treatment with $\mathrm{Zn}$ and Mo. POD activity after $\mathrm{Zn}$ exposure (a); POD activity after Mo exposure (b). Values are represented as means $\pm S D$; different letters denote significant differences at $p<0.05$.

increased SOD activity to some degree. The maximum SOD activity was observed at $0.5 \mathrm{mM}$ Mo concentration, while all Zn treatments decreased the enzyme activity, compared to the control. A gradual increase in SOD activity was observed up to $0.5 \mathrm{mM}$ Mo treatment. Zn treatments at 0.5-2.5 mM concentrations resulted in statistically similar SOD activity.

Consistently higher POD activities were found as results of $\mathrm{Zn}$ treatments (Fig. 5a). The elevated POD activity was observed to be stable with a small but statistically significant increase as the concentration of $\mathrm{Zn}$ in the media increased. In contrast, exposure to Mo resulted in variable changes in POD activity, which did not correlate with increasing metal concentrations (Fig. 5b). The Mo concentration-dependent bursts in POD activity seemed to be alleviated at moderate concentrations. However, POD activity reached its maximum value at the highest Mo concentration.

The CAT activity pattern was similar to POD activities as the metal concentrations changed in the media (Fig. 6a and 6b). Starting from the lowest concentration, all $\mathrm{Zn}$ treatments resulted in significant CAT activity increase, and this increase was similar regardless of the increasing concentrations of $\mathrm{Zn}$ (Fig. 6a). A statistically significant increase in POD activity was observed after $0.5 \mathrm{mM}$ Mo treatment. Then, a similar activity pattern to POD activity was observed in CAT activities, with increasing Mo concentrations (Fig. 6b). CAT activity was the lowest in the control and the cultures exposed to $0.1 \mathrm{mM}$ Mo. Among the antioxidant enzymes investigated in this study, 
greater stimulation was observed for POD and CAT activity, while SOD was found to be induced significantly only after Mo treatments.

\section{Discussion}

Heavy metal exposure and accumulation can result in physiological and developmental disorders in plants. Reduced organ growth, limitations in photosynthesis due to reduced pigment synthesis and increased chloroplast deformation, over-production of antioxidant enzymes, accumulation of some osmoregulators, and increased lipid peroxidation are the most common signs of stress-related responses in plants $(4,24)$.

Our findings revealed that additional Mo up to concentrations of $5.0 \mathrm{mM}$ in the medium did not cause any reduction in shoot growth, whereas even the lowest concentration $(0.1$ $\mathrm{mM}$ ) of Mo suppressed root growth. High molybdenum concentrations of up to $1000 \mathrm{ppm}$ in the culture medium can be tolerated by plants (25). However, only trace amounts of Mo are required for the healthy development of plants. Thus there is a narrow range between optimal and toxic amounts (26), and our findings support this view. Apart from the direct effect of Mo at high concentrations, organ development inhibition by Mo might arise through an indirect mechanism related to sulfate uptake. Mendel (8) reported that nonspecific sulfate/phosphate transporters also participate in Mo uptake, in addition to the high-affinity Mo transporter. It has been reported that high levels of Mo in culture medium interfere with sulfate (S) uptake and assimilation (27). S deficiency will also compromise plant organ development (28), in addition to the deleterious effects of high Mo concentrations. Adverse effects of external Mo supply on S assimilation have previously been demonstrated in Trifolium repens which supports this hypothesis (9).

Inhibition of root and shoot growth, curling, chlorosis, and necrosis in leaves are the common symptoms of $\mathrm{Zn}$ toxicity in plants (7). In the present study, additional $\mathrm{Zn}$ at concentrations higher than $0.5 \mathrm{mM}$ in the culture medium inhibited root development in $A$. orientalis, whereas concentrations up to $1.0 \mathrm{mM}$ promoted shoot growth. The inhibitory effect of excess $\mathrm{Zn}$ on root development may be explained by the breakdown of root cortex cells while the inhibition of shoot development at higher $\mathrm{Zn}$ concentrations can be attributed to the breakdown of vascular bundles, decrease in intercellular space and reduction in epidermal and palisade cell size (29). As root growth appears to be inhibited by lower concentrations of $\mathrm{Zn}$, one explanation for the inhibitory effect of $\mathrm{Zn}$ on shoot growth may be that, because of a lack of root function, shoot development is indirectly inhibited rather than being directly impaired by $\mathrm{Zn}$ as this effect was only seen after complete root development inhibition. This indicates that $A$. orientalis can tolerate a certain level of $\mathrm{Zn}$ in its root system, but after root development and function are impaired, it would limit the transport of this metal to the shoots. A similar mechanism was shown in Cistus monspeliensis under Zn stress (30). However, further experiments would be required to prove these hypotheses concerning Mo and $\mathrm{Zn}$ transport from the culture medium to the shoots of $A$. orientalis.
Although the plants treated with an additional 0.1 Mo had statistically the same results as controls, the increasing Mo concentration reduced total protein contents. The reduction in protein content due to additional $\mathrm{Zn}$ exposure was found to be more pronounced than with Mo. Excess Mo can cause a deficiency of other mineral nutrients, such as Magnesium (Mg), which is essential for RNA function and thereby protein biosynthesis $(31,32)$. Therefore, any limitation in $\mathrm{Mg}$ uptake can lead down-regulation of protein synthesis. In the cultures of $A$. orientalis exposed to increasing Mo concentrations, the decline in soluble protein content may be attributed to this indirect effect of excess Mo.

Compared to controls, a gradual decrease in protein contents was found in plants treated with increasing $\mathrm{Zn}$. $\mathrm{Zn}$ is one of the major cofactors of numerous enzymes such as carbonic anhydrase, $\mathrm{Cu} / \mathrm{Zn} \mathrm{SOD}$, and matrix metalloproteinases. $\mathrm{Zn}$ is also involved in protein synthesis (33). Ramakrishna and Rao (34) reported that total soluble protein content decreased in Raphanus sativus treated with $5 \mathrm{mM} \mathrm{Zn}$. Long term exposure to high Zn triggers oxidative stress in plants, which could further result in denaturation of functional and structural proteins and disturbed cellular redox homeostasis (7). Thus, ROS-mediated protein denaturation might be the cause of reduced protein content in A. orientalis treated with higher $\mathrm{Zn}$ levels.

Osmoprotectants, such as sugars, cyclic and acyclic polyols, fructans, amino acids, and amino acid derivatives, and quaternary amino and sulfonium compounds, take part in cell membrane stabilization processes during several abiotic stresses in plants (35). As one of the major osmoprotectants, proline $\alpha$-amino acid plays a role in membrane stabilization. During mild Mo stress in A. orientalis, proline accumulation slightly increased, but exposure to the highest Mo concentrations significantly elevated proline concentration. This trend in proline accumulation followed a similar pattern to $\mathrm{H}_{2} \mathrm{O}_{2}$ production. However, the pattern of MDA accumulation differed from these. This finding indicated that proline accumulation in $A$. orientalis could repress membrane damage. Proline accumulation due to $\mathrm{Zn}$ stress was more pronounced than that due to Mo stress in $A$. orientalis. Increased proline accumulation by $\mathrm{Zn}$ stress followed a dose-dependent pattern, as did MDA and $\mathrm{H}_{2} \mathrm{O}_{2}$ accumulation. However, oxidative burst at the highest $\mathrm{Zn}$ levels did not trigger MDA formation of the same magnitude. This kind of membrane stabilization effect can be attributed to a significantly increased proline level. This pattern of synchronized accumulation of proline and $\mathrm{H}_{2} \mathrm{O}_{2}$ due to $\mathrm{Zn}$ stress has also been reported in Citrus reticulate (36). To fully understand the physiology of osmoregulation mechanisms in A. orientalis, changes not only in proline but also in soluble sugars, sugar alcohols, and glycine betaine should also be considered.

MDA is frequently used as a biomarker of ROS-mediated cellular damage after oxidative stress $(33,37)$. An increase in MDA content indicates increased peroxidation of cell membrane lipids, and MDA measurement provides a means of estimating the intensity of the stress and extent of its damaging effects (24). In our study, both Mo and $\mathrm{Zn}$ treatments increased 
MDA production. However, MDA contents were found to be increased gradually as $\mathrm{Zn}$ concentrations increased, whereas no difference was found among MDA levels caused by increased Mo levels. The observed increase in MDA levels after Zn treatments coincided with increased ROS levels, but no such correlation was found between MDA and ROS production after Mo exposure. Kumchai et al. (38) concluded that under conditions of excess Mo antioxidant enzyme activity increases, probably to scavenge ROS in Brassica oleracea var. capitata. A similar mechanism might be proposed in A. orientalis whereby antioxidant enzymes are increased which actively scavenge excess ROS, thereby limiting cellular damage due to Mo stress. Dai et al. (39) found that $\mathrm{Zn}$ treatments between 300 and $900 \mu \mathrm{M}$ caused the simultaneous accumulation of MDA and ROS in Medicago sativa cultivars. In A. orientalis, the continuous accumulation of MDA indicated that enhanced proline production was insufficient to stabilize cell membranes against oxidation during $\mathrm{Zn}$ stress. A further mechanism may be that increased cell membrane permeability and lipid peroxidation could lead to the loss of integrity of the membranes of root cells, which would further negatively affect the water absorption capacity of the roots (40).

The most common ROS are ${ }^{1} \mathrm{O}_{2}, \mathrm{O}_{2}^{-}, \mathrm{H}_{2} \mathrm{O}_{2}$, and ${ }^{\circ} \mathrm{OH}$. They are highly reactive molecules that can oxidize membrane lipids and biomolecules, leading to cell membrane damage and cause degradation of enzymes, proteins, and nucleic acids, consequently harming cell integrity. $\mathrm{H}_{2} \mathrm{O}_{2}$ has a multifunctional role since the molecule acts as a messenger in the plant's defense system but also can cause cellular damage if over-produced. As a result of cellular activities, ROS are produced through the electron transport chain. However, some enzymes such as plasma-membrane-localized NADPH oxidases, amine oxidases, and cell wall peroxidases can be additional sources of $\mathrm{H}_{2} \mathrm{O}_{2}$ generation (41). The increase in $\mathrm{H}_{2} \mathrm{O}_{2}$ concentrations was of greater magnitude for a given concentration of $\mathrm{Zn}$ than that of equivalent concentrations of Mo in A. orientalis. Rout and Das (42) found that exposure to Mo increased the activity of POD and CAT in Oryza sativa, which suggests that $\mathrm{H}_{2} \mathrm{O}_{2}$ production would also be increased. The increased generation of $\mathrm{H}_{2} \mathrm{O}_{2}$ with subsequent increased activity in antioxidant scavenging mechanisms under $\mathrm{Zn}$ stress has been reported in many plants, including several wild Prunus (43) and Brassica species (37). It is likely that a similar situation would occur in A. orientalis, and our results support this. The changes in antioxidant enzyme activities and $\mathrm{H}_{2} \mathrm{O}_{2}$ concentration after $\mathrm{Zn}$ exposure showed that A. orientalis is highly susceptible to $\mathrm{Zn}$, and increased antioxidant enzyme activities following $\mathrm{Zn}$ exposure is not sufficient to scavenge all ROS produced at the concentrations used in our experiments.

In plants, the enzymatic defense system is stimulated to rapidly-produce antioxidant enzymes in response to several biotic and/or abiotic factors. An increase in the antioxidant enzyme activities and maintenance of this enzymatic system play critical roles in the decomposition of ROS and thereby in the stabilization of cell membranes. The decomposition of ROS is due to the action of antioxidant enzymes, such as superoxide dismutase (SOD), catalase (CAT), and peroxidases (POD). SOD enzyme converts superoxide radicals into either $\mathrm{O}_{2}$ or $\mathrm{H}_{2} \mathrm{O}_{2}$, while CAT and POD decompose $\mathrm{H}_{2} \mathrm{O}_{2}$ to $\mathrm{H}_{2} \mathrm{O}$ and $\mathrm{O}_{2}$, cooperatively. The bulk of $\mathrm{H}_{2} \mathrm{O}_{2}$ in the cell is removed by CAT, whereas the $\mathrm{H}_{2} \mathrm{O}_{2}$, which has not been decomposed by CAT is scavenged by POD (44). In our study, all Mo concentrations resulted in higher SOD activity than controls whereas increased $\mathrm{Zn}$ levels alleviated SOD activity in $A$. orientalis. The elevation of SOD activity after Mo exposure on drought-stressed Triticum aestivum had been reported (45). Our results also showed that Mo excess might be considered as a stimulant for the antioxidant defense system but only up to a point because, after $2.5 \mathrm{mM} \mathrm{Mo}$, the survival of the plant is unlikely since the root development is inhibited. Protein damage due to ROS accumulation can cause a decrease in enzyme activity, especially in SOD, in susceptible plants (46). In our study, $\mathrm{Zn}$ treatments resulted in decreased SOD activities while $\mathrm{H}_{2} \mathrm{O}_{2}$ levels increased, which may be due to protein damage. At this point, several osmoprotectants, such as proline, start to play more important roles and may suppress ROS accumulation and lipid peroxidation, as well as improving membrane integrity (47). Proline accumulation during $\mathrm{Zn}$ stress in A. orientalis supports this suggestion. Peroxidases in A. orientalis have been classified as "Class III" which is composed of secretory enzymes such as glycoproteins (48) while its catalase was found to have a single subunit and $75 \mathrm{kDa}$ molecular weight (49). Increasing POD activity was also reported in Glycine max (50) and Triticum aestivum (51) after Mo and $\mathrm{Zn}$ treatments, respectively. In a recent study on $A$. orientalis, it was shown that elevated POD activity and nearly unchanged CAT activity catalyzed the transformation of $\mathrm{H}_{2} \mathrm{O}_{2}$ to $\mathrm{H}_{2} \mathrm{O}$ and protected the plant against drought stress (5). The increases in POD and CAT activities after Zn/Mo exposure were more pronounced than was found following salt and drought stresses in A. orientalis (4). The notable increases in POD but nearly unchanged activities of CAT after salt and drought stress suggested that CAT has only a supplementary role in $\mathrm{H}_{2} \mathrm{O}_{2}$ regulation in A. orientalis. However, the marked increase in both POD and CAT activities after $\mathrm{Zn} / \mathrm{Mo}$ stress validates the supposition of a co-operative relationship between these two enzymes. These observations also suggest that the extent of this cooperation depends on the type of stress factor.

\section{Conclusions}

Redox metals can directly generate oxidative injury in plants. Redox-inactive metals, such as Mo and Zn, indirectly stimulate oxidative stress through various mechanisms, which can result in deleterious disorders such as oxidation of protein and lipids, redox imbalance, and denaturation of cell structure and membrane. In the current study, we analyzed some of these mechanisms and their outcomes on a plant species, A. orientalis, that is a high priority for conservation in its native habitat. The present study has revealed that $A$. orientalis is highly susceptible to excess $\mathrm{Zn}$, and cannot tolerate exposure to concentrations greater than $0.1 \mathrm{mM}$. However, the plant can tolerate Mo 
up to $2.5 \mathrm{mM}$ concentration. Deficiency of Mo is more common than its toxicity in nature. Therefore $\mathrm{Zn}$ contamination in soil should be primarily considered as one of the major threats for A. orientalis in the environment. This study has also shown that the supplementary role of CAT against drought and salt stress can be switched into more balanced cooperation with POD under long-term $\mathrm{Zn} /$ Mo stress.

\section{Acknowledgments}

The authors would like to thank Mr. Jeremy Jones, of the Kocaeli University Academic Writing Department, for his help with the English used in this paper. This work was supported by The Scientific and Technological Research Council of Turkey (TÜBITAK) under grant number 113Z609. We are very grateful to Halil İbrahim Toygar and Aygül Kına for their assistance with experiments.

\section{Conflict of Interest}

The authors declare that they have no conflicts of interest.

\section{Ethical Compliance}

This article does not contain any studies involving human participants or animals performed by any of the authors.

\section{References}

1. Acemi A, Özen F, Kıran R. In vitro propagation of Amsonia orientalis Decne. from nodal segments of adult plants. Propag Ornam Plants 2013; 13: 25-32.

2. Özen F. Autoecology of a species being endangered in Turkey: Amsonia orientalis Decne. (Apocynaceae). Journal of Balikesir University Institute of Science and Technology 2006; 8: 4-9.

3. Bern Convention. 1979. Convention on the conservation of European wildlife and natural habitats. Available via https://rm.coe. int/CoERMPublicCommonSearchServices/DisplayDCTMContent?documentld $=0900001680304354$

4. Acemi A, Duman Y, Karakuş YY, Kömpe YÖ, Özen F. Analysis of plant growth and biochemical parameters in Amsonia orientalis after in vitro salt stress. Hortic Environ Biotechnol 2017; 58: 231239.

5. Acemi A, Avcı Duman Y, Karakuş YY, Özen F. Developmental and biochemical analyses of in vitro drought stress response in ornamental European Bluestar (Amsonia orientalis Decne.). Folia Hortic 2018; 30(2): 405-414.

6. Tchounwou PB, Yedjou CG, Patlolla AK, Sutton DJ. Heavy metal toxicity and the environment. Exp Suppl. 2012; 101: 133-164.

7. Anjum NA, Singh HP, Khan MIR, Masood A, Per TS, Negi A, Batish DR, Khan NA, Duarte AC, Pereira E, Ahmad I. Too much is bad-an appraisal of phytotoxicity of elevated plant-beneficial heavy metal ions. Environ Sci Pollut R 2015; 22: 3361-3382.

8. Mendel RR. The molybdenum cofactor. J Biol Chem 2013; 288: 13165-13172.

9. Zhang Q, Lee B-R, Park S-H, Jeong G-O, Kim T-H. Molybdate alters sulfate assimilation and induces oxidative stress in white clover (Trifolium repens L.). J Kor GrassI Forage Sci 2013; 3(3): 153-158.

10. Kumchai J, Huang JZ, Lee CY, Chen FC, Chin SW. The induction of antioxidant enzyme activities in cabbage seedlings by heavy metal stress. Int J Biol Biomol Agri Food \& Biotech Eng. 2013; 7(1): 41-46.

11. Emamverdian A, Ding Y, Mokhberdoran F, Xie Y. Heavy Metal Stress and Some Mechanisms of Plant Defense Response. Sci World J 2015; 756120.

12. Helena M, Carvalho C. Drought stress and reactive oxygen spe- cies. Plant Signal Behav 2008; 3(3): 156-165.

13. Dong $X, B i H, W u G, A i X$. Drought-induced chilling tolerance in cucumber involves membrane stabilisation improved by antioxidant system. Int J Plant Prod 2013; 7(1): 67-80.

14. Gürkanlı CT, Özkoç İ, Aydın EB, Acemi A, Özen F. Genetic diversity of Amsonia orientalis. Biologia 2014; 69: 742-749.

15. Acemi A, Özen F, Kıran R. Development of an efficient callus production protocol for Amsonia orientalis: A critically endangered medicinal plant. Eurasia J Biosci 2012; 6: 105-112.

16. Murashige T, Skoog F. A revised medium for rapid growth and bioassays with tobacco tissue cultures. Physiol Plantarum 1962; 15: 473-497.

17. Bradford M. A rapid and sensitive method for the quantification of microgram quantities of protein using the principle of protein-dye binding. Anal Biochem 1976; 72: 248-254.

18. Bates LS, Waldren RP, Teare ID. Rapid determination of free proline for water stress studies. Plant Soil 1973; 39: 205-207.

19. Neto ADA, Prisco JT, Enéas-Filho J, Abreu CEB, Gomes-Filho E. Effect of salt stress on antioxidative enzymes and lipid peroxidation in leaves and roots of salt-tolerant and salt-sensitive maize genotypes. Environ Exp Bot 2006; 56(1): 87-94.

20. Doupis G, Chartzoulakis K, Beis A, Patakas A. Allometric and biochemical responses of grapevines subjected to drought and enhanced ultraviolet-B radiation. Aust J Grape Wine Res. 2011; 17: 36-42.

21. Dhindsa RS, Plumb-Dhindsa P, Thorpe TA. Leaf senescence: Correlated with increased levels of membrane permeability and lipid peroxidation, and decreased levels of superoxide dismutase and catalase. J Exp Bot 1981; 32: 93-101.

22. Kar M, Mishra D. Catalase, peroxidase, polyphenol oxidase activities during rice leaf senescence. Plant Physiol 1976; 57: 315-319.

23. Aebi H. 1974. Methods of enzymatic analysis. In: Catalase. Bergmeyer H.U. (Ed.), Academic Press, New York, USA, 673-675.

24. Ozdener Y, Aydin BK. The effect of zinc on the growth and physiological and biochemical parameters in seedlings of Eruca sativa (L.) (Rocket). Acta Physiol Plant 2010; 32: 469-476.

25. McGrath SP, Micó C, Curdy R, Zhao FJ. Predicting molybdenum toxicity to higher plants: influence of soil properties. Environ Pollut 2010; 158: 3095-3102.

26. McBride MB, Richards BK, Steenhuis T, Spiers G. Molybdenum uptake by forage crops grown on sewage sludge-amended soils in the field and greenhouse. J Environ Qual 2000; 29: 848e854.

27. Schiavon M, Pilon-Smits EAH, Wirtz M, Hell R, Malagoli M. Selenate and molybdate alter sulfate transport and assimilation in Brassica juncea L. Czern.: implications for phytoremediation. Environ Exp Bot 2012; 75: 41-51.

28. Saha S, Samad R, Rashid P, Karmoker JL. Effects of sulphur deficiency on growth, sugars, proline and chlorophyll content in mungbean (Vigna Radiata L. Var. Bari Mung-6). Bangladesh J Bot 2016; 45(2): 405-410.

29. Maruthi Sridhar BB, Han FX, Diehl SV, Monts DL, Su Y. Effects of Zn and $\mathrm{Cd}$ accumulation on structural and physiological characteristics of barley roots. Braz J Plant Physiol 2007; 19: 15-22.

30. Arenas-Lago D, Carvalho LC, Santos ES, Manuela Abreu M. The physiological mechanisms underlying the ability of Cistus monspeliensis L. from São Domingos mine to withstand high Zn concentrations in soils. Ecotox Environ Safe 2016; 129: 219-227.

31. Brune A, Dietz KJ. A comparative analysis of element composition of roots and leaves of barley seedlings grown in the presence of toxic cadmium, molybdenum, nickel and zinc concentrations. J Plant Nutr 1995; 18: 853-868.

32. Broadley M, Brown P, Cakmak I, Rengel Z, Zhao F. 2012. Function of Nutrients: Micronutrients. In: Marschner P (ed) Marschner's Mineral Nutrition of Higher Plants, Academic Press, USA, pp 191-248.

33. Cakmak I. Possible roles of zinc in protecting plant cells from dam- 
age by reactive oxygen species. New Phytol 2000; 146: 185-205.

34. Ramakrishna B, Rao SSR. 24-Epibrassinolide alleviated zinc-induced oxidative stress in radish (Raphanus sativus $L$.) seedlings by enhancing antioxidative system. Plant Growth Regul 2012; 68(2): 249-259.

35. Cushman JC. Osmoregulation in Plants: Implications for Agriculture. Am Zool 2001; 41(4): 758-769.

36. Subba P, Mukhopadhyay M, Mahato SK, Bhutia KD, Mondal TK, Ghosh SK. Zinc stress induces physiological, ultra-structural and biochemical changes in mandarin orange (Citrus reticulata Blanco) seedlings. Physiol Mol Biol Plants 2014; 20(4): 461-473.

37. Feigl G, Lehotai N, Molnár Á, Ördög A, Rodríguez-Ruiz M, Palma $J M$, Corpas FJ, Erdei L, Kolbert Z. Zinc induces distinct changes in the metabolism of reactive oxygen and nitrogen species (ROS and RNS) in the roots of two Brassica species with different sensitivity to zinc stress. Ann Bot 2015; 116: 613-625.

38. Kumchai J, Huang JZ, Lee CY, Chen FC, Chin SW. Proline partially overcomes excess molybdenum toxicity in cabbage seedlings grown in vitro. Genet Mol Res 2013; 12(4): 5589-5601.

39. Dai H-P, Shan C-J, Zhao H, Li C-J, Jia G-L, Jiang H, Wu S-Q, Wang Q. The difference in antioxidant capacity of four alfalfa cultivars in response to Zn. Ecotoxicol Environ Safety 2015; 14: 312-317.

40. Oliva SR, Mingorance MD, Leidi EO. Tolerance to high $\mathrm{Zn}$ in the metallophyte Erica andevalensis Cabezudo \& Rivera. Ecotoxicology 2012; 21: 2012-2021.

41. Caverzan A, Casassola A, Patussi Brammer S. 2016. Reactive Oxygen Species and Antioxidant Enzymes Involved in Plant Tolerance to Stress. In: Shanker A (ed) Abiotic and Biotic Stress in Plants - Recent Advances and Future Perspectives, InTech, pp 463-480.

42. Rout GR, Das P. Rapid hydroponic screening for molybdenum tolerance in rice through morphological and biochemical analysis. Rostlinná Výroba 2002; 48: 505-512.

43. Sorkheh K, Shiran B, Khodambashi M, Rouhi V, Mosavei S, Sofo A. Exogenous proline alleviates the effects of $\mathrm{H}_{2} \mathrm{O}_{2}$ induced oxidative stress in wild almond species. Russ J Plant Physiol 2012; 59(6): 788798.
44. Willekens $\mathrm{H}$, Chamnongpol S, Davey M, Schraunder M, Langebartels C, Van Montagu M, Inzé D, Van Camp W. Catalase is a sink for $\mathrm{H}_{2} \mathrm{O}_{2}$ and is indispensable for stress defence in C3 plants. EMBO J 1997; 16: 4806-4816.

45. Wu S, Hu C, Tan Q, Nie Z, Sun X. Effects of molybdenum on water utilization, antioxidative defense system and osmotic-adjustment ability in winter wheat (Triticum aestivum) under drought stress. Plant Physiol Biochem 2014; 83: 365-374.

46. Perveen S, Shahbaz M, Ashraf M. Modulation in activities of antioxidant enzymes in salt stressed and non-stressed wheat (Triticum aestivum $\mathrm{L}$.) plants raised from seed treated with triacontanol. Pak J Bot 2011; 43: 2463-2468.

47. Banu NA, Hoque A, Watanabe-Sugimoto M, Matsuoka K, Nakamura Y, Shimoishi Y, Murata Y. Proline and glycinebetaine induce antioxidant defense gene expression and suppress cell death in cultured tobacco cells under salt stress. J Plant Physiol 2009; 166(2): 146-156.

48. Yuzugullu Karakus Y, Acemi A, Işık S, Duman Y. Purification of peroxidase from Amsonia orientalis by three-phase partitioning and its biochemical characterization. Sep Sci Technol 2018; 53: 756766.

49. Avcı Duman Y, Acemi A, Yuzugullu Y, Özen F. Separation of catalase from Amsonia orientalis with single step by aqueous two-phase partitioning system (ATPS). Sep Sci Technol 2018; 52: 691-699.

50. Liu P, Yang YS, Xu GD, Fang YH, Yang YA, Kalin RM. The effect of molybdenum and boron in soil on the growth and photosynthesis of three soybean varieties. Plant Soil Environ 2005; 51: 197-205.

51. Li X, Yang Y, Jia L, Chen H, Wei X. Zinc-induced oxidative damage, antioxidant enzyme response and proline metabolism in roots and leaves of wheat plants. Ecotox Environ Safe 2013; 89: 150-157. 